\title{
Improving Nutrition, Physicochemical and Antioxidant Properties of Rice Noodles with Fiber and Protein-rich Fractions Derived from Cassava Leaves
}

\author{
Thidarat Poonsri ${ }^{1}$, Shima Jafarzadeh ${ }^{2}$, Fazilah Ariffin ${ }^{2, *}$, Syahariza Zainul Abidin ${ }^{2}$, \\ Ziba Barati ${ }^{3}$, Sajid Latif ${ }^{3}$, Joachim Müller ${ }^{3}$

\begin{abstract}
${ }^{1}$ Program in Food Technology, School of Agro-Industry, Mae Fah Luang University, Chiang Rai 57100, Thailand
${ }^{2}$ Food Technology Division, School of Industrial Technology, University Sains Malaysia, 11800 Minden, Penang, Malaysia ${ }^{3}$ Institute of Agriculture Engineering (440e), Tropics and Subtropics Group, University of Hohenheim, 70599 Stuttgart, Germany *Corresponding author: fazilah@usm.my
\end{abstract}

Received February 10, 2019; Revised March 28, 2019; Accepted April 18, 2019

\begin{abstract}
Introduction: Noodles are rich in fibre and important nutrients which help promote health. This study was an attempt to determine the impacts of using different levels of cassava leaves on antioxidant features, nutritional values, and the quality of rice noodles. Methods: Wheat flour and rice were used to prepare rice noodles which used cassava leaves which were on the basis of flour weight $(0,10,20,30$ and $40 \%)$. The proximate analysis, antioxidant activities, texture, color, and total cyanide content of the noodles were then determined. Results: The present findings suggest that using cassava leaves at different levels helps modify the structure of the noodles, finally leading to a softer product in comparison with the control samples. Furthermore, the addition of cassava leaves increased the amount of protein and fiber content and improved the antioxidant activities of rice noodles. Conclusion: It could be implied that cassava leaves with a lot of advantageous components -could be a great ingredient to enhance antioxidant features and nutritional value (protein and fiber) of noodle.
\end{abstract}

Keywords: rice noodle, cassava leaves, antioxidant activities, proximate analysis, texture

Cite This Article: Thidarat Poonsri, Shima Jafarzadeh, Fazilah Ariffin, Syahariza Zainul Abidin, Ziba Barati, Sajid Latif, and Joachim Müller, "Improving Nutrition, Physico-chemical and Antioxidant Properties of Rice Noodles with Fiber and Protein-rich Fractions Derived from Cassava Leaves." Journal of Food and Nutrition Research, vol. 7, no. 4 (2019): 325-332. doi: 10.12691/jfnr-7-4-10.

\section{Introduction}

The rice noodle is known as a famous variety of Asian noodles and is widely eaten in Southeast Asia [1]. Rice noodles are produced from rice flour, which is sometimes mixed with other components. Produced from long-grain rice, laksa or rice noodles are known as traditional cuisine containing intermediate to high amylose content (>22\%) [2]. Laksa noodle is different from rice vermicelli; it looks like white spaghetti and has larger diameter [3]. Although rice noodles abound in carbohydrate, they often have a paucity of important nutritious elements including dietary fiber, protein, antioxidation, and vitamins. Todays, secondary features such as functional and nutritional are important to consumers [4].

Today, the wide use of banana flour, rye flour and black rice flour substitute rice flour for increasing the important nutritional elements including vitamins, dietary fiber, and protein. Nevertheless, cassava leaves have been used as raw material, therefore, it is time now to focus our attention to incorporate the cassava leaves as a source nutrient for human nutrition as well as to encourage their value as an addition to food product. Cassava (Manihot esculenta, Crantz) is abundantly found in subtropical and tropical regions such as Latin America, Asia, and Africa. It is estimated that nearly 276.7 million tons of Cassava are produced [5].

The cassava plant is most commonly used for its starchy tubers; its leaves are regarded as a by-product which is still underutilized. Large tonnages of these leaves are currently discarded as wastes after harvesting the roots [6]. On the one hand, they are popular fertilizers and animal food [7]; on the other hand, on a dry matter basis, cassava leaves abound $25 \%$ protein and provide a great amount of calcium, iron, and vitamins $\mathrm{C}$ and A. they are also known for their antioxidant function that helps lower the process of aging and promotes the endurance of body against the disease. Cassava leaf protein has important amino acid which is similar to amino acid in the eggs of hen [8].

Concerning accessibility, expense, and fiber, it seems that cassava leaves are more likely to be used as a great source of dietary fiber. However, there is no literature indicating the consumption of cassava leaves dietary fiber in rice noodle (laksa) products. Therefore, this study aimed to use cassava leaves by adding it in rice noodle (laksa) to 
increase the essential nutrition and elucidate the effects of using cassava leaves incorporation on the rice noodles' qualities such as chemical and physical features and nutrition.

\section{Materials and Methods}

\subsection{Raw Material}

Cassava leaves collected from Kulim, Kedah, Malaysia. Modified cassava flour (MOCAF) is prepared by fermenting lactic acid bacteria from Penang Malaysia. Salt, wheat, and rice flour were purchased from the local market in Penang Malaysia.

The chemicals used in this research were Gallic acid, Folin-Ciocalteu reagent, 1,1-diphenyl- 2-picrylhydrazyl (DPPH), ferric chloride hexahydrate, 2,4,6-tripyridyl- striazine, ammonia solution, potassium iodide, silver nitrate (AgNO3) solution, Kjedahl catalyst tablets and Petroleum ether which were purchased from Sigma Chemical Co. All other reagents and solvent were of analytical grade.

\subsection{Preparation of Cassava Leaves}

Cassava leaves were pounded into small pieces and boiled in boiling water at $100^{\circ} \mathrm{C}$ for 5 minutes. After that, cassava leaves were removed from boiling water and drained for 5 minutes. Then, cassava leaves were blended with water at ratio 80:20 (cassava leaves/water; w/v) in a blender (Panasonic, MX-900M blender). Slurry of cassava leaves was obtained and used as an ingredient for rice noodle.

\subsection{Preparation of Rice Noodles with Cassava Leaves}

The rice noodles were prepared by mixed rice flour, cassava flour, and cassava leaves in ratios 45:0:0, 40:5:0, 40:5:10, 40:5:20, 40:5:30 and 40:5:40 RF(g):CF(g):CL(g): (rice flour/cassava flour/cassava leaves). The rice noodle without cassava leaves was prepared as a control. Wheat flour $2.8 \mathrm{~g}$ and salt $0.6 \mathrm{~g}$ were added to each formulation. Furthermore, water was added to each flour mix to obtain slurry. After that, the slurry was extruded using the kitchen extruder (Die diameter $0.4 \mathrm{~mm}$ ) into boiling water at $100^{\circ} \mathrm{C}$ for 5 minutes. Then, the cooked rice noodles were placed in cool water for 1 minute and drained after 5 minutes. Rice noodles were packed in vacuum bags and kept at $4^{\circ} \mathrm{C}$ for further analysis.

\subsection{Proximate Analysis}

On the basis of AOAC (2000), the Kjeldahl method was used to measure nitrogen which was also used to convert crude protein $(\mathrm{N} \times 5.7)$. Being extracted with petroleum ether in a Soxhlet apparatus, crude fat was evaluated via a gravimetric method [9]. Having being incinerated at $550^{\circ} \mathrm{C}$ for $24 \mathrm{~h}$ in a furnace, ash content was measured by a gravimetric method. Drying the samples at $105^{\circ} \mathrm{C}$ overnight helped measuring moisture content. A TDF assay kit (Megazyme International Ireland, Wicklow, Ireland) was employed to measure Total dietary fibre (TDF) content. In light of the AOAC method 996.11 [9], a total carbohydrate assay kit (Megazyme International Ireland, Wicklow,
Ireland) was used to measure the carbohydrate content The analysis of composition was done in triplicate.

\subsection{Total Cyanide Content}

The alkaline titration method was used to determine the content of cyanide. $200 \mathrm{~cm} 3$ distilled water was mixed with 20 grams of the rice noodle in a liter round bottom flask. The flask mixture was kept for 3 hours. It was, then, steamed so that $150 \mathrm{~cm} 3$ of distillate could be gained. After that, the distillated received twenty-centimeter cube of $0.02 \mathrm{M}$ sodium hydroxide solution and the volume had some changes in cyanide of cassava soak forming up to $250 \mathrm{~cm} 3$ in a volumetric flask. Two aliquots (each 100 $\mathrm{cm} 3$ ) were gained from the distillate. $2 \mathrm{~cm} 3$ of $5 \%$ potassium iodide solution and $8 \mathrm{~cm} 3$ of $6 \mathrm{M}$ ammonia solution were added to each of the aliquots. $0.02 \mathrm{M}$ silver nitrate solution (AgNO3) was used to titrate the final mixture. As soon as there is a change from clear to a faint turbid solution, it could be implied that the titration has reached an end point. Instead of cassava distillate, 150 $\mathrm{cm} 3$ of distillate water was used to prepare a blank sample $5.0 \mathrm{~g}$. The following relation is used to determine the content of cyanide in the sample: $1 \mathrm{~cm} 3 \quad 0.02 \mathrm{M}$ AgNO3=1.08 mg HCN.

\subsection{Total Polyphenol Content}

Based on a method described by the International Organization for Standardization (ISO) 14502-1, spectrophotometry was used to determine the total polyphenol content (TPC) employing gallic acid as a standard. Tubes which contain $5.0 \mathrm{~mL}$ of a $1 / 10$ dilution of Folin-Ciocalteu's reagent in water were used to hold $1.0 \mathrm{~mL}$ of the diluted sample extract. After that, $4.0 \mathrm{~mL}$ of a sodium carbonate solution $(7.5 \% \mathrm{w} / \mathrm{v})$ was added to the extract. Then, the tubes were kept at room temperature for one hour. Then, UV-vis spectrophotometer, (Shimadzu, UV mini-1240, Kyoto, Japan) was used to determine absorbance at $765 \mathrm{~nm}$. The TPC was considered to be gallic acid equivalents (GAE) in g/100 g sample. The polyphenol concentration in samples comes from a standard curve of gallic acid.

\subsection{DPPH Free Radical Scavenging Assay}

The bleaching of the purple colored DPPH methanol solution was used to measure electron donation function and the hydrogen atom of the given extracts [10]. Some pure compounds were also measured in the same way. Based on a method developed by Braca et al. [11], the extracts' antioxidant activity was measured on the basis of the scavenging activity of the stable 1,1-diphenyl-2picrylhydrazyl $(\mathrm{DPPH})$ radical. The extract $(0.1 \mathrm{ml})$ was added to $2.9 \mathrm{ml}$ pf a $0.004 \%$ DPPH solution in methanol. The samples will be first kept in a dark place for $30 \mathrm{~min}$. Then, absorbance was measured at $517 \mathrm{~nm}$ using UV-vis spectrophotometer, (Shimadzu, UV mini-1240, Kyoto, Japan) and the percent inhibition (I\%) of activity was calculated as:

$$
\mathrm{DPPH}-\mathrm{RSA}(\%)=\frac{\left(\begin{array}{l}
\text { Absorbance of control } \\
- \text { Absorbance of sample }
\end{array}\right)}{\text { Absorbance of control }} \times 100
$$




\subsection{Ferric Reducing Antioxidant Power Assay (FRAP)}

The FRAP assay was used to determine the total antioxidant activity in the extract. Extract ) $200 \mu \mathrm{L}$ ( was added to FRAP reagent )3 mL, 10 parts $300 \mathrm{mM}$ sodium acetate buffer at $\mathrm{pH}$ 3.6, $10 \mathrm{mM} \mathrm{2,4,6-tri(2-pyridyl)-s-}$ triazine (TPTZ) solution and $20 \mathrm{mM} \mathrm{FeCl} 6 \mathrm{H} 2 \mathrm{O}$ solution) and the reaction mixture was incubated in a water bath at $37^{\circ} \mathrm{C}$ for $30 \mathrm{~min}$. The increase in absorbance was measured at $593 \mathrm{~nm}$ using UV-vis spectrophotometer, (Shimadzu, UV mini-1240, Kyoto, Japan). The percent inhibition was calculated as:

$$
I \%=\frac{\left(\begin{array}{l}
\text { Absorbance of sample } \\
- \text { Absorbance of control }
\end{array}\right)}{\text { Absorbance of sample }} \times 100 \text {. }
$$

\subsection{Texture}

As explained in detail by Bhattacharya et al. [1n 2], a texture analyzer (TA.XT.plus, Stable Micro Systems Ltd., Godalming, UK) was used to measure texture profile analysis (TPA) of rice noodles. A cylinder probe (35.0mm diameter) was used to compress a strand of cooked noodle with $1.0 \mathrm{~mm}$ thickness. The speed of pre-test was $5 \mathrm{~mm} / \mathrm{s}$ while the speeds of the test and post-test speeds were $1 \mathrm{~mm} / \mathrm{s}$. The distance of target was $3 \mathrm{~mm}$. The compress process was done twice for each single test sample and decompression followed each compression. The interval between the second compression and the end of the first compression lasted 5 seconds. The term hardness was used for the first peak force, and the term adhesiveness was used to describe the curve's negative force area during probe retraction. Dividing the area of the second compression by the area of the first cycle results in cohesiveness. Concerning each group, approximately10 individual strands were assessed. The findings are presented as an average of the measurements.

\subsection{Color}

The color factor of rice noodle was determined using colorimeter (Minolta, CM-3500d, Tokyo, Japan). Greenness or redness was represented b-y -a/+a represents, represented the lightness of color $(0=$ black; $100=$ white $)$ was represented by coordinates ' $L$ ', and blueness or yellowness are represented by $-\mathrm{b} /+\mathrm{b}$. The raw noodles were put over the spectrocolorimeter port, they were then placed in a blackened container in order to block ambient light. Assessments were done in triplicate.

\subsection{Statistical Analysis}

One-way statistical analysis (ANOVA) was used to analyze the data based Duncan test in the experiments. All data were processed using SPSS package (SPSS 22.0 for Windows, SPSS Inc, Chicago, Illinois, U.S.A) and expressed as mean value \pm standard deviation. The significant level was set at $\mathrm{P}>0.05$.

\section{Results and Discussions}

\subsection{Proximate Composition}

The proximate composition of rice noodle with different percentage of cassava leaves are shown in Table 1. As expected, the addition of cassava leaves increased the non-carbohydrate component, particularly the crude protein and crude fiber content of rice noodles because cassava leaves are high in protein (17.7-38.1\% DW) and fiber content $(0.5-10 \%)$ [13]. It seems that protein of cassava leaf has more level of amino acids than that of spinach leaves, rice grain, oat, and soybean; however, there are a number of factors contributing to this great amount of amino acid in cassava leaf protein such as cultivar, analysis method, stage of maturity, conditions of climate, and the amount of leaf sample [14]. The noodles' quality, toughness, and texture are influenced by content of protein. Ngudi et al. [15] believes that boiling causes methionine content to decrease by $71 \%$ and protein content by $58 \%$. It seems that after cooking, cassava leaves' free amino acids dramatically drop [16]. While crude fiber tended to increase as there was an increase in the percentage of adding cassava leaves in rice noodles compared with control.

Table 1 displays noodles' the average ash content analysis. Cassava leaf increased the noodles' ash content which is about $0.13-0.21 \%$. The cassava leaf's mineral impacts the noodles' ash content. Fat and carbohydrate decreased but not significantly as there was an increased in the percentage of adding cassava leaves.

\subsection{Cyanide Content}

Over 100 ppm total cyanide could be found in cassava leaves (fresh weight basis) and cassava leaves are reported to be extremely poisonous [17]. Cassava have three forms of free cyanide, cyanohydrins, and cyanogens viz. cyanogenic glucoside (95\% linamarin and 5\% lotaustralin) [18]. There are several factors that affect the amount of cyanogenic including environmental conditions like drought, which causes in the level of cyanogenic, cultivars, the status of soil nutrient, and locations [19]. World Health Organization suggests $10 \mathrm{ppm}$ of cyanide in food (FAO/WHO, 1995). In this experiment, cyanide demonstrated a lower level of content than the level is recommended by the FAO, which is safe for consuming. As Figure 1 displays, there is no significant change in the level of cyanide as cassava leaves is increased compare with control samples. As Zhou et al [20] found, some part of cyanide content could be lost during the soaking and cooking processes of cassava. Concerning this experiment, pounding and boiling in water helped prepare the cassava leaves. It seems that these two processes led into losing some amount of content in cassava leaves. Bradbury and Denton [21] confirmed that boiling pounded cassava leaves in water (a traditional method) can cause all cyanogens to be removed even at the expense of losing nutritious ingredients. Having being chopped, as soon as cassava leaves are boiled, nearly $85 \%$ of cyanogenic glucosides are lost in presence of water [22]. 
Table 1. Proximate composition of rice noodle

\begin{tabular}{|c|c|c|c|c|c|c|}
\hline Sample (g) & Moisture & Ash & Protein & Fat & Fiber & Carbohydrate \\
\hline Control (RF)* & $69.50 \pm 0.31^{\mathrm{a}}$ & $0.13 \pm 0.01^{\mathrm{a}}$ & $2.28 \pm 0.12^{\mathrm{a}}$ & $2.34 \pm 0.80^{\mathrm{a}}$ & $0.77 \pm 0.15^{\mathrm{e}}$ & $24.98 \pm 0.75^{\mathrm{a}}$ \\
\hline 5g substitute RF with CF* & $70.72 \pm 0.68^{\mathrm{b}}$ & $0.15 \pm 0.02^{\mathrm{a}}$ & $2.41 \pm 0.19^{\mathrm{ab}}$ & $1.79 \pm 0.43^{\mathrm{a}}$ & $0.85 \pm 0.07^{\mathrm{e}}$ & $24.08 \pm 1.32^{\mathrm{a}}$ \\
\hline 10gcassava leaves & $70.75 \pm 0.32^{\mathrm{b}}$ & $0.21 \pm 0.01^{\mathrm{ab}}$ & $2.57 \pm 0.04^{\mathrm{b}}$ & $1.82 \pm 0.36^{\mathrm{a}}$ & $2.75 \pm 0.10^{\mathrm{d}}$ & $22.25 \pm 0.33^{\mathrm{b}}$ \\
\hline $20 \mathrm{~g}$ cassava leaves & $71.63 \pm 0.24^{\mathrm{bc}}$ & $0.21 \pm 0.04^{\mathrm{ab}}$ & $2.85 \pm 0.09^{c}$ & $1.77 \pm 0.37^{\mathrm{a}}$ & $3.22 \pm 0.19^{c}$ & $20.89 \pm 0.46^{\mathrm{c}}$ \\
\hline $30 \mathrm{~g}$ cassava leaves & $71.79 \pm 0.80^{\mathrm{bc}}$ & $0.28 \pm 0.01^{\mathrm{b}}$ & $2.90 \pm 0.24^{c}$ & $1.77 \pm 0.37^{\mathrm{a}}$ & $4.44 \pm 0.14^{\mathrm{b}}$ & $19.64 \pm 0.54^{\mathrm{cd}}$ \\
\hline $40 \mathrm{~g}$ cassava leaves & $72.02 \pm 0.72^{\mathrm{c}}$ & $0.28 \pm 0.10^{\mathrm{b}}$ & $2.97 \pm 0.10^{c}$ & $1.65 \pm 0.64^{\mathrm{a}}$ & $5.44 \pm 0.26^{\mathrm{a}}$ & $19.80 \pm 0.99^{\mathrm{d}}$ \\
\hline
\end{tabular}

Values are expressed as means $\pm \mathrm{SD}(\mathrm{n}=3)$. Means followed by the same letters within the same column are not significant at $\mathrm{P}>0.05$. * $\mathrm{RF}=\mathrm{rice}$ flour, $\mathrm{CF}=$ cassava flour.

5

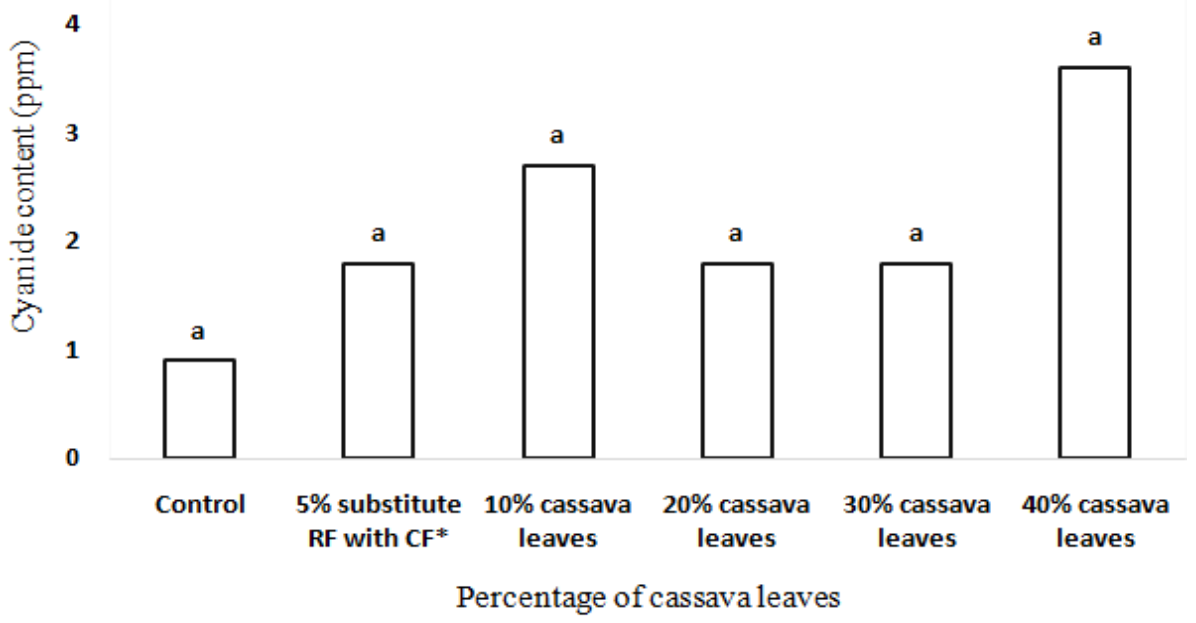

Figure 1. Cyanide content of rice noodle with different concentration of cassava leaves. Value are express as mean \pm standard deviation ( $\mathrm{n}=3$ ). Mean with same letter are not significant at $\mathrm{P}>0.05$. ${ }^{*} \mathrm{RF}=$ Rice flour, $\mathrm{CF}=\mathrm{Cassava}$ four

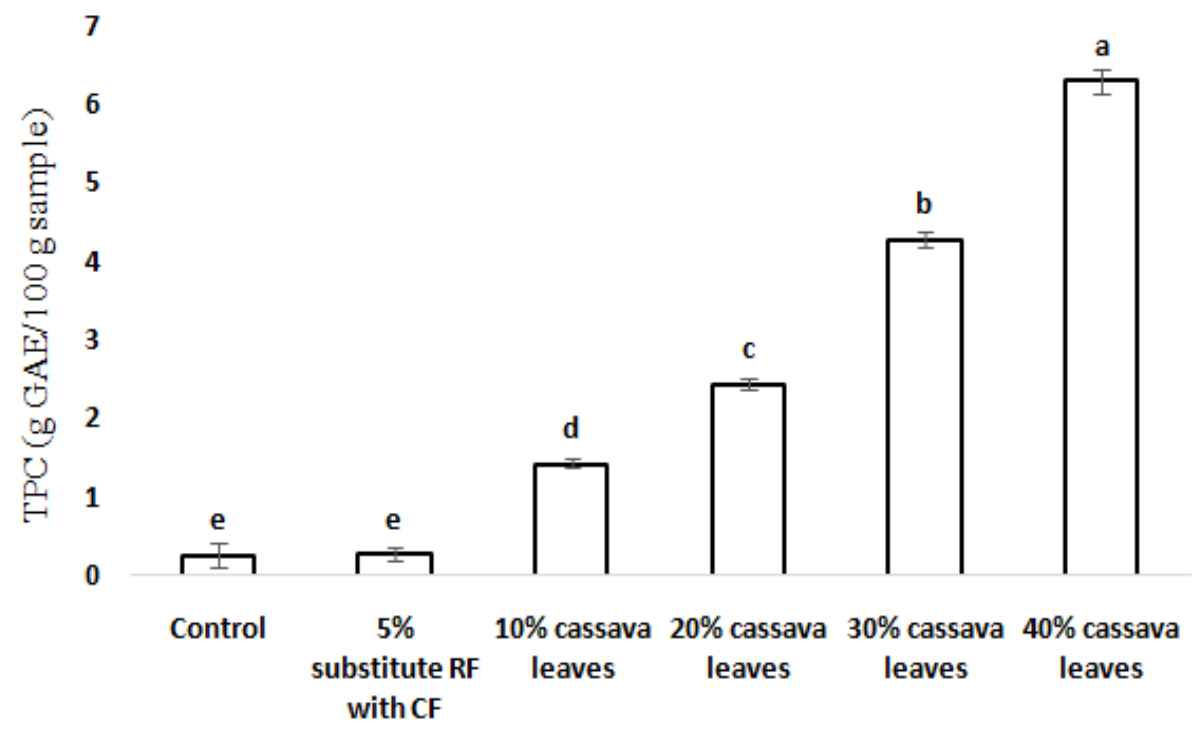

Percentage of cassava leaves

Figure 2. Total polyphenol content of rice noodle with different concentration of cassava leaves. Value are express as mean \pm standard deviation ( $=3$ ). Mean with same letter are not significant at $\mathrm{P}>0.05 .{ }^{*} \mathrm{RF}=$ Rice flour, $\mathrm{CF}=$ Cassava four

\subsection{Total Polyphenol Content}

The total polyphenol content (TPC) in noodles can be seen in Figure 2. The results showed TPC significantly increased when the percentage of cassava leaves increased in rice noodles compared with control. Total polyphenol of control was not significantly different with 5\% substitute rice flour with cassava flour since it had the lowest amount of polyphenols while the highest amount of polyphenol was observed in rice noodles with $40 \%$ of cassava leaves. Generally, a sample that contains a high amount of polyphenols also exhibits a high antioxidant activity. Rice noodles with cassava leaves, which showed high antioxidant activities (Figure 3), also had high TPC and it tended to increase as there was an increase in the percentage of cassava leaves.

Catechin and its derivatives are reported to be the polyphenols found in cassava [23]. The polyphenols are 
reported to be in the same class of compounds which are related with cardiovascular health advantage popular in green tea [24]. Mostly the leaves' polyphenolic compounds are considered as tannin equivalents and shown in a non-specific way [22]. Although polyphenols are reported to be great antioxidants, they contain essential minerals in their compound which hampers their beneficial absorption.

\subsection{Antioxidant Activity}

\subsubsection{DPPH Free Radical Scavenging Activity}

The primary antioxidant activities were measured using the stable radical DPPH. These activities are commonly concerned with the free radical scavenging activities of food materials, extracts of fruit and plant, and pure antioxidant compounds. The main benefit of cassava leaves for the long term is that it can be a healthy natural anti-oxidant. One leaf of cassava contains vitamin C which can prevent the effects of free radicals that endanger the health of the body. In this study, the antioxidant activity of rice noodle was expressed as percentage of inhibition (\%). The DPPH free radical scavenging activity of rice noodles are shown in Figure 3. Based on the antioxidation activity, the percentage of inhibition tended to increase when there was an increase in the percentage addition of cassava leaves. Based on $\mathrm{DPPH}$ inhibition, the highest percentage was found in rice noodles with $40 \%$ of cassava leaves while control was not significantly different with $5 \%$ substitute rice flour with cassava flour as it showed the lowest percentage of inhibition. Present result is in agreement with what found by Novelina [25], who reported an increase in the proportion of cassava leaf extract can cause an increase in the wet noodles' antioxidant activity. Novelina [25] also found that cassava leaf's chlorophyll increases the level of the wet noodles' antioxidant. According to present findings, it could be implied that antioxidation activity is greatly influenced by cassava leaves which could naturally generate an antioxidation protection.

\subsubsection{Ferric Ion Reducing Activity}

Higher values of FRAP indicate a higher capacity of antioxidant since FRAP value depends on lowering ferric ion, where antioxidants play the role of the reducing elements. The compounds of antioxidants are able to give a hydrogen atom or single electron for lowering ferric ion [10]. The results (Figure 4) showed that the FRAP scavenging activities of rice noodles was not very different from their DPPH scavenging activities. Similar to the results obtained for the DPPH scavenging assay rice noodle, FRAP scavenging activity tended to increase when the percentage addition of cassava leaves increased. Except for rice noodle that had 30\% of cassava leaves, it was not significantly different from rice noodles that had $20 \%$ and $40 \%$ of cassava leaves. Based on FRAP inhibition, the highest percentage was found in rice noodles that had $40 \%$ of cassava leaves while control was not significantly different with $5 \%$ substitute rice flour with cassava flour since it showed the lowest percentage of inhibition. However, FRAP scavenging activities values were higher than those obtained for DPPH scavenging activities. The presence of compounds, which do not react to DPPH, could be assumed the possible reason for reducing the plants' values of DPPH scavenging activity. Although some antioxidant compounds such as polyphenols could efficiently reduce ferric iron, some of these compounds may not efficiently scavenge DPPH free radicals because of steric hindrance [16].

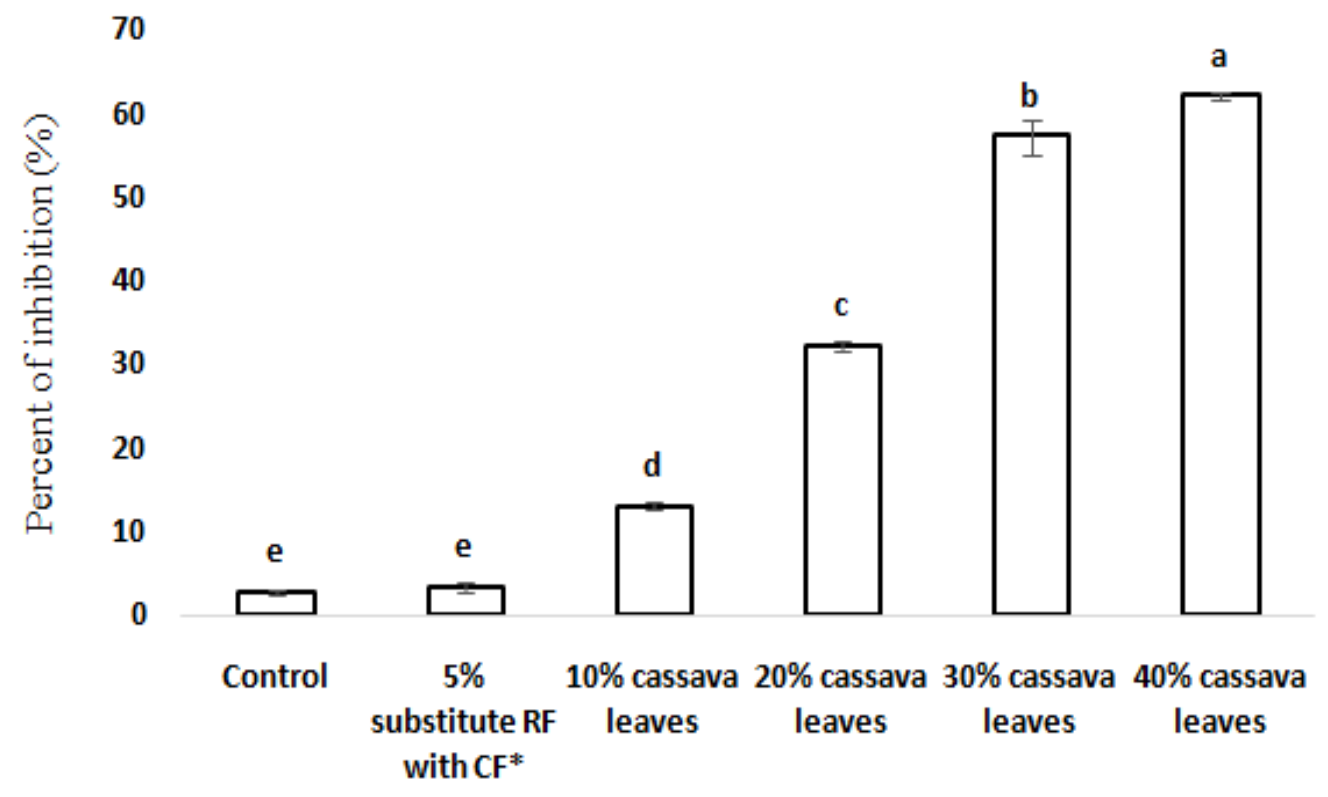

\section{Percentage of cassava leaves}

Figure 3. DPPH scavenging activities of rice noodle with different concentration of cassava leaves. Value are express as mean \pm standard deviation $(\mathrm{n}=3)$. Mean with same letter are not significant at $\mathrm{P}>0.05$, ${ }^{*} \mathrm{RF}=$ Rice flour, $\mathrm{CF}=\mathrm{Cassava}$ four 


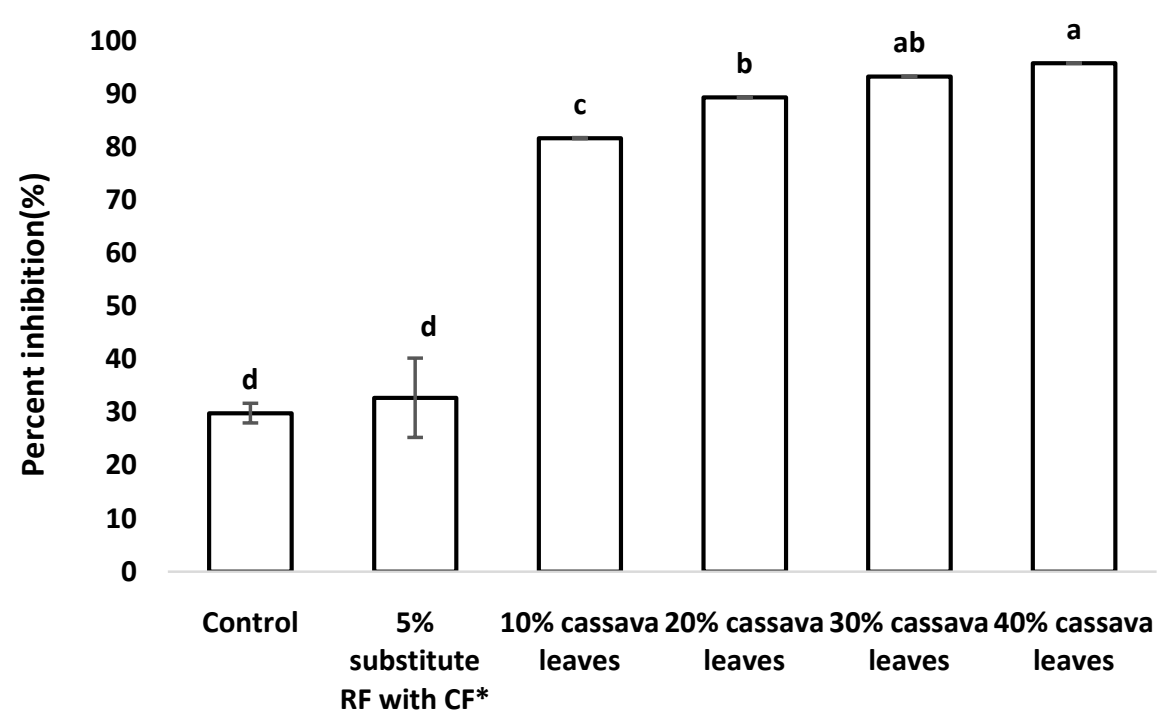

Percentage of cassava leaves

Figure 4. FRAP scavenging activities of rice noodle with different concentration of cassava leaves. Value are express as mean \pm standard deviation $(\mathrm{n}=3)$. Mean with same letter are not significant at $\mathrm{P}>0.05$. *RF= Rice flour, $\mathrm{CF}=\mathrm{Cassava}$ four.
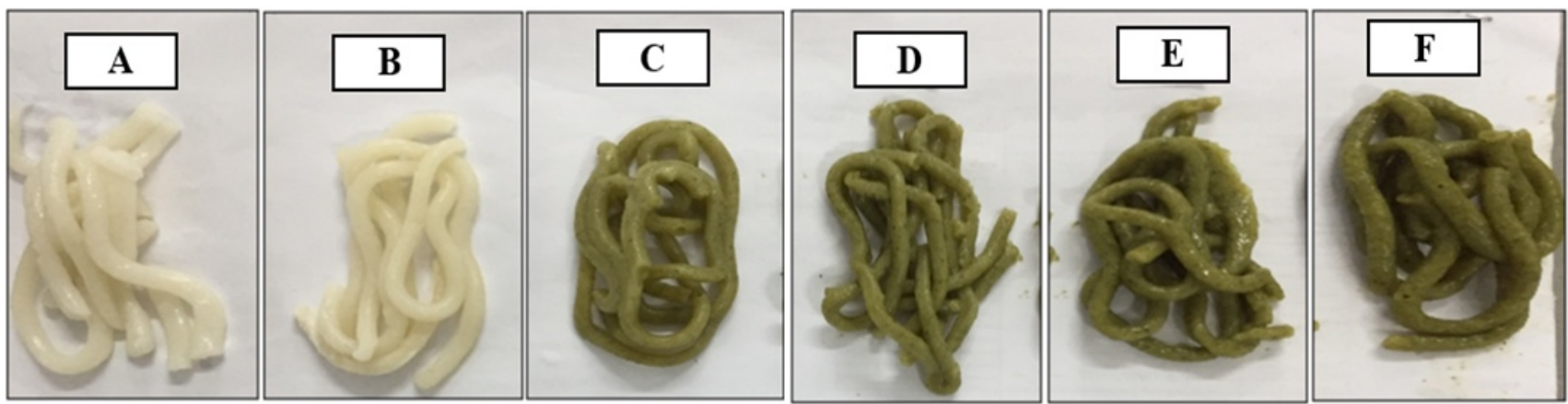

Figure 5. The characteristic of rice noodle with different percentage addition of cassava leaves. $A=$ control, $B=5 \%$ substitute rice flour with cassava flour, $\mathrm{C}=10 \%$ addition of cassava leaves, $\mathrm{D}=20 \%$ cassava leaves, $\mathrm{E}=30 \%$ cassava leaves, $\mathrm{F}=40 \%$ cassava leaves

\subsection{Textural Properties}

Textural properties are the most critical characteristics when quality and consumers' acceptance of cooked noodles are evaluated [12]. Texture features of rice noodles with different percentage of cassava leaves are presented in Table 2. The hardness of the noodle (force per area) dictates noodle bite, which is expressed as soft bite or hard bite. In the present study the hardness of rice noodles tended to reduce when the percentage addition of cassava leaves increased. However, hardness value of rice noodles (5\% substitute rice flour with cassava flour) was lower than that of control. The presence of phenolic hydroxyl groups probably leads to this observation. Since phenolic hydroxyl groups interact with other types of reactive groups and they easily fit into the noodles' polysaccharides network, this increases the free volume of the noodle matrix. These findings are in line with the results of previous studies [26,27]. According to the literature, using phenolic compounds leads to changes in the mechanical features, which in turn lower hardness. As shown in Table 2, the results indicated that both adhesiveness and cohesiveness showed similar trends. There were no significant difference except for rice noodles with $40 \%$ of cassava leaves, which was significantly different from control. For gumminess and chewiness, there was a likelihood of a decrease in gumminess and chewiness as there was an increase in the percentage of cassava leaves. On the other hand, there were no significant differences in springiness. The matrix structural network of glutens, starches, fibers, proteins, and other additional ingredients greatly impacts noodles' the textural features. As a result, this could either improve or loosen the hydrogen bonds' formation within the structure network of noodles.

\subsection{Color}

It seems that color plays a significant role in the customers' daily lives since they constantly encounter a wide range of colors. This diversity of colors deeply impacts consumers' preferences when it comes buying an item in a particular environment. In addition to texture, the next important feature of noodles is color because it is one of the first things that a customer notices.

Color parameter of rice noodles with different percentage of cassava leaves was shown in Table 3. Adding different percentages of cassava leaves change the color characteristic of rice noodles (Figure 5). The lightness $\left(\mathrm{L}^{*}\right)$ of rice noodles ranged from 42.10 to 76.40. An increase in the percentage of cassava leaves significantly decreased the lightness of rice noodles. 
Table 2. Texture attribute of rice noodle with different percentage of cassava leaves

\begin{tabular}{ccccccc}
\hline Sample & Hardness & Adhesiveness & Springiness & Cohesiveness & Gumminess & Chewiness \\
\hline Control & $4889.77 \pm 372.75 \mathrm{a}$ & $-559.27 \pm 205.73 \mathrm{~b}$ & $0.84 \pm 0.06 \mathrm{a}$ & $0.48 \pm 0.07 \mathrm{ab}$ & $2338.75 \pm 476.30 \mathrm{a}$ & $1935.61 \pm 260.57 \mathrm{a}$ \\
\hline $\mathbf{5 \%}$ substitute RF with CF* & $3923.83 \pm 111.01 \mathrm{~b}$ & $-630.39 \pm 168.95 \mathrm{~b}$ & $0.76 \pm 0.03 \mathrm{a}$ & $0.49 \pm 0.07 \mathrm{ab}$ & $1933.80 \pm 320.91 \mathrm{ab}$ & $1468.02 \pm 200.76 \mathrm{~b}$ \\
\hline $\mathbf{1 0 \%}$ cassava leaves & $3583.37 \pm 132.71 \mathrm{bc}$ & $-430.19 \pm 84.70 \mathrm{ab}$ & $0.81 \pm 0.04 \mathrm{a}$ & $0.50 \pm 0.03 \mathrm{ab}$ & $1783.84 \pm 90.80 \mathrm{~b}$ & $1439.03 \pm 131.06 \mathrm{~b}$ \\
\hline $\mathbf{2 0 \%}$ cassava leaves & $3469.14 \pm 372.72 \mathrm{bc}$ & $-516.31 \pm 144.68 \mathrm{ab}$ & $0.79 \pm 0.03 \mathrm{a}$ & $0.48 \pm 0.01 \mathrm{ab}$ & $1666.98 \pm 139.86 \mathrm{bc}$ & $1322.41 \pm 132.29 \mathrm{~b}$ \\
\hline $\mathbf{3 0 \%}$ cassava leaves & $3290.38 \pm 221.42 \mathrm{c}$ & $-487.18 \pm 53.83 \mathrm{~b}$ & $0.79 \pm 0.01 \mathrm{a}$ & $0.45 \pm 0.00 \mathrm{~b}$ & $1491.20 \pm 99.72 \mathrm{bc}$ & $1172.17 \pm 84.40 \mathrm{bc}$ \\
\hline $\mathbf{4 0 \%}$ cassava leaves & $2280.47 \pm 49.86 \mathrm{~d}$ & $-206.53 \pm 43.54 \mathrm{a}$ & $0.80 \pm 0.06 \mathrm{a}$ & $0.56 \pm 0.02 \mathrm{a}$ & $1274.16 \pm 40.45 \mathrm{c}$ & $1017.14 \pm 88.82 \mathrm{c}$ \\
\hline
\end{tabular}

Values are expressed as means $\pm \mathrm{SD}(\mathrm{n}=3)$. Means followed by the same letters within the same column are not significant at $\mathrm{P}>0.05$. * RF=rice flour, $\mathrm{CF}=$ cassava flour.

Table 3. Color parameter of rice noodle with different percentage of cassava leaves

\begin{tabular}{|c|c|c|c|}
\hline Sample & $\mathbf{L}^{*}$ & $\mathrm{a}^{*}$ & $\mathbf{b}^{*}$ \\
\hline Control & $76.40 \pm 0.03^{\mathrm{a}}$ & $-1.70 \pm 0.05^{\mathrm{a}}$ & $10.63 \pm 0.02^{\mathrm{e}}$ \\
\hline $5 \%$ substitute $\mathrm{RF}$ with $\mathrm{CF}^{*}$ & $76.35 \pm 0.06^{\mathrm{a}}$ & $-1.87 \pm 0.04^{\mathrm{b}}$ & $10.47 \pm 0.02^{\mathrm{e}}$ \\
\hline $10 \%$ cassava leaves & $53.56 \pm 0.02^{\mathrm{b}}$ & $-2.07 \pm 0.05^{c}$ & $24.62 \pm 0.29^{d}$ \\
\hline $20 \%$ cassava leaves & $49.15 \pm 0.02^{\mathrm{c}}$ & $-2.19 \pm 0.08^{\mathrm{d}}$ & $25.75 \pm 0.02^{\mathrm{c}}$ \\
\hline $30 \%$ cassava leaves & $43.13 \pm 0.04^{\mathrm{d}}$ & $-2.33 \pm 0.04^{\mathrm{e}}$ & $26.50 \pm 0.02^{\mathrm{b}}$ \\
\hline $40 \%$ cassava leaves & $42.10 \pm 0.01^{\mathrm{e}}$ & $-2.27 \pm 0.04 \mathrm{~d}^{\mathrm{e}}$ & $28.18 \pm 0.03^{\mathrm{a}}$ \\
\hline
\end{tabular}

Values are expressed as means $\pm \mathrm{SD}(\mathrm{n}=3)$. Means followed by the same letters within the same column are not significant at $\mathrm{P}>0.05$. * $\mathrm{RF}=$ rice flour, $\mathrm{CF}=$ cassava flour.

The value of $\mathrm{a}^{*}$ color parameter ranged from -2.27 to -1.70 which represents variation from green to red. A* value was negative value implying that the color of rice noodles became green. Green color of rice noodles significant increased when there was an increase in the percentage addition of cassava leaves. $\mathrm{B}^{*}$ value of rice noodle ranged from 10.63 to 28.18 which represented variation from blue to yellow. As there was an increase in the addition of cassava leaves to rice noodles, the rice noodle became more yellow, as recorded by an increase in positive $b^{*}$ values. Heaton and Marangoni [28] believe that the loss of chlorophyll is one of the common reported changes in the green plants. Concerning the processed foods, the chlorophyll loss changes the color from brilliant green to olive brown; this also leads to a wide range of colors including brown, yellow, and orange in senescent tissues. Therefore, after cooking rice noodle, the color of rice noodles became yellow. The incorporation of natural pigment not only promotes the sensory features of food but also functionally enhances the nutrition quality of food [29].

\section{Conclusion}

The present research improved the physico-chemical, nutritional and antioxidant properties of rice noodle by adding cassava leaves. The present findings in this study stress the likelihood of incorporating fibre and protein rich fractions, which come from processing of the agricultural products, in order to promote rice noodles' nutritional values and qualities. In general, protein and fiber content of rice noodles increased by adding cassava leaves because cassava leaves are high in protein and fiber. Compared to the control, rice noodles with different percentage addition of cassava leaves had an improvement in their antioxidant activities and polyphenol content.
Furthermore, cyanide content reduced during pounding and boiling in water and the amount of cyanide content was lower than the FAO maximum recommended level which makes it safe for consuming cassava leaves. According to the current findings, it could be suggested that cassava leaves could be used as a great ingredient in order to enhance noodles' antioxidant features and nutritional values.

\section{Statement of Competing Interests}

This article does not contain any studies with human participants or animals performed by any of the authors.

\section{Acknowledgments}

Authors are grateful to BMBF (Bundesministerium für Bildung und Forschung), Germany for providing support under the project CassavaUpgrade (031B0217).

\section{References}

[1] Hormdok, R. \& Noomhorm, A (2007) Hydrothermal treatments of rice starch for improvement of rice starch noodle quality. LWTFood Sci and Tech 40: 1723-1731.

[2] Choi, S. Y., \& Koh, B. K. (2017). Effects of Annealing and Removal of the Water-Soluble Fraction of Dry-Milled Rice Flour on the Texture of Cooked Rice Noodles. Food and Nut Sci 8: 885.

[3] Nura, M., Kharidah, M., Jamilah, B., \& Roselina, K. (2011). Textural properties of laksa noodle as affected by rice flour particle size. J Int Food Res, 18: 1309-1312.

[4] Gunathilake, K. D. P. P., \& Abeyrathne, Y. M. R. K. (2008). Incorporation of coconut flour into wheat flour noodles and evaluation of its rheological, nutritional and sensory characteristics. j Food process pres 32: 133-142. 
[5] Faostat, D. (2013). Food and agriculture organization of the United Nations. Statistical database. FAO/WHO food Standards Programme, Codex Alimentarius Commission (Vol. Codex Standard 176_1989). Rome, Italy.

[6] Nassar, N. M., \& Marques, A. O. (2006). Cassava leaves as a source of protein. J Food Agr Envon, 4: 187.

[7] Keaokliang, O., Kawashima, T., Angthong, W., Suzuki, T., \& Narmseelee, R. (2018). Chemical composition and nutritive values of cassava pulp for cattle. Animal Science Journal.

[8] Salata, C. D. C., Leonel, M., Trombini, F. R. M., \& Mischan, M. M. (2014). Extrusion of blends of cassava leaves and cassava flour: physical characteristics of extrudates. Food Sci Tech, 34: 501-506.

[9] AOAC. (2000). Official Methods of Analysis, 17th ed Washington, DC: Association of Official Analytical Chemists.

[10] Cuendet, M., Hostettmann, K., Potterat, O., \& Dyatmiko, W. (1997). Iridoid glucosides with free radical scavenging properties from Fagraea blumei. Helvetica Chimica Acta 80:1144-1152.

[11] Braca, A., De Tommasi, N., Di Bari, L., Pizza, C., Politi, M., \& Morelli, I. (2001). Antioxidant principles from bauhinia $t$ arapotensis. Journal of natural products 64: 892-895.

[12] Bhattacharya, M., Zee, S.Y. \& Corke, H. (1999). Physicochemical properties related to quality of rice noodles. Cereal Chem 76: 861-867.

[13] Parmar, A., Sturm, B., \& Hensel, O. (2017). Crops that feed the world: Production and improvement of cassava for food, feed, and industrial uses. Food Security 9: 907-927.

[14] Oguntimein, G. B. (1988). Processing cassava for animal feed. In L. R. S. K. Hahn, \& G. N. Egbunike (Eds.), Potential of cassava as livestock feed in Africa. IITA/ILCA/University of Ibadan.

[15] Ngudi, D. D., Kuo, Y. H., \& Lambein, F. (2003a). Amino acid profiles and protein quality of cooked cassava leaves or 'saka-saka'. J Sci Food Agr 83: 529-534.

[16] Ngudi, D. D., Kuo, Y. H., \& Lambein, F. (2003b). Cassava cyanogens and free amino acids in raw and cooked leaves. Food and Chem Toxico, 41: 1193-1197.

[17] Latif, S., \& Müller, J. (2015). Potential of cassava leaves in human nutrition: a review. Trends Food Sci Tech 44:147-158.

[18] Montagnac, J. A., Davis, C. R., \& Tanumihardjo, S. A. (2009). Nutritional value of cassava for use as a staple food and recent advances for improvement. Comp reviews in food sci food safety, 8: 181-194.

[19] Burns, A. E., Gleadow, R. M., Zacarias, A. M., Cuambe, C. E., \& Miller, R. E. (2012). Variations in the chemical composition of cassava (Manihot esculenta Crantz) leaves and roots as affected by genotypic and environmental variation. J Agr Food Chem, 60: 4946-4956.

[20] Zhou, W., Yang, J., Hong, Y., Liu, G., Zheng, J., Gu, Z., \& Zhang, P. (2015). Impact of amylose content on starch physicochemical properties in transgenic sweet potato. Carbohydrate polymers, 122 417-427.

[21] Bradbury, J. H., \& Denton, I. C. (2014). Mild method for removal of cyanogens from cassava leaves with retention of vitamins and protein. Food Chemistry, 158, 417-420.

[22] Montagnac, J. A., Davis, C. R., \& Tanumihardjo, S. A. (2009a). Processing techniques to reduce toxicity and antinutrients of cassava for use as a staple food. Comprehensive Reviews in Food Science and Food Safety 8: 17-27.

[23] Uritani, I. (1999). Biochemistry on postharvest metabolism and deterioration of some tropical tuberous crops. Botanical Bulletin of Academia Sinica, 40.

[24] Basu, A., \& Lucas, E. A. (2007). Mechanisms and effects of green tea on cardiovascular health. Nutrition reviews, 65: 361-375.

[25] Novelina, Anggraini T. \& Hermansyah R. (2015). Production of Liquid Chlorophyll from The Leaves of Green Grass Jelly (Premna oblongifolia Merr.). Int J on Advanced Sci Eng Information Tech. 2088- 5334.

[26] Arcan I, Yemenicioglu A. (2011). Incorporating phenolic compounds opens a new perspective to use zein films as flexible bioactive packaging materials. Food Res Int 44: 550-6.

[27] Laohakunjit N, Noomhorm A. (2004). Effect of plasticizers on mechanical and barrier properties of rice starch film. Starch/Staerke 56:348-56.

[28] Heaton, J. W., \& Marangoni, A. G. (1996). Chlorophyll degradation in processed foods and senescent plant tissues. Trends in Food Sci Tech, 7: 8-15.

[29] Kong, S., Kim, D. J., Oh, S. K., Choi, I. S., Jeong, H. S., \& Lee, J. (2012). Black rice bran as an ingredient in noodles: chemical and functional evaluation. J food sci, 77(3). 